\title{
Traduzindo Pensamento e Letramento Estatístico em Atividades para Sala de Aula: construção de um produto educacional
}

\author{
Translating Thinking and Statistical Literacy Activities for the Classroom: \\ building an educational product
}

Mario de Souza Santana*

\begin{abstract}
Resumo
O presente trabalho se propõe a apresentar a construção de um produto educacional para o ensino e aprendizagem da Estatística discutindo os fundamentos teóricos que a embasaram. Além disso, pretende mostrar apontamentos, que podem configurar-se em orientações, a respeito da condução das atividades por parte do docente visando a uma maior eficácia quando da utilização de tal proposta didático-metodológica. Tais apontamentos decorrem de levantamento bibliográfico prévio e das percepções que emergiram durante sua implementação em uma turma de $3^{\circ}$ ano do Ensino Médio e posteriores análises feitas nesse teste avaliativo, pesquisa de campo. Também, como parte integrante dessa construção, será exemplificada sua aplicação por meio das atividades desenvolvidas junto aos estudantes. Todo esse processo se sustenta numa pesquisa de mestrado desenvolvida junto ao Programa de Mestrado Profissional em Educação Matemática da Universidade Federal de Ouro Preto.
\end{abstract}

Palavras-chave: Pensamento Estatístico. Ciclo Investigativo. Letramento Estatístico. Educação Matemática Crítica. Atividades Investigativas.

\begin{abstract}
This study presents the construction of an educational product for teaching and learning of Statistics through discussion of the theoretical foundations that substantiate statistics. It also aims to show notes, which can set up guidelines regarding the conduction of activities by the teacher with a view to greater efficiency when using such didactic and methodological proposition. Such matters comes from a previous literature review and perceptions that emerged during its implementation in a High School Senior class (3rd year of high school) and further analysis that was made in this evaluation test, field research. As part of this construction, its application is exemplified by the activities with students. This entire process is based on a Master's Degree research developed by the Professional Master's Program in Mathematics Education at the Federal University of Ouro Preto.
\end{abstract}

Keywords: Statistical Thinking. Investigative Cycle. Statistical Literacy. Critical Mathematics Education. Investigative Activities.

\section{Introdução}

\footnotetext{
* Mestre em Educação Matemática pela Universidade Federal de Ouro Preto (UFOP). Docente do Instituto Federal do Norte de Minas Gerais (IFNMG), Araçuaí, Minas Gerais, Brasil. Endereço para correspondência: Fazenda do Meio Pé da Serra, s/n, BR 367, km 278 (Estrada Araçuaí/Itaobim), Araçuaí/MG, CEP: 39600-000, Brasil. E-mail: mario.santana@ifnmg.edu.br.
} 
Não é incomum a Estatística ser ensinada (e "aprendida") sob a égide de um paradigma tradicional no qual se privilegiam os procedimentos, técnicas e algoritmos, fundamentados na repetição e resolução de uma série de exercícios padrão. Nesse cenário, privilegiam-se os conteúdos da Estatística Descritiva, ensinados através da aplicação mecânica das fórmulas das medidas de posição, dispersão, construção de tabelas e gráficos etc., a partir de dados secundários, em geral fictícios, simplesmente transcritos do livro didático, que pouco têm a ver com a realidade sociocultural dos estudantes.

Nessa prática de ensino, árida e descontextualizada, tão comum quando se trata da Matemática, indagamos acerca de certas características do conhecimento estatístico, seu potencial no desenvolvimento de algumas competências e sobre possibilidades didáticometodológicas que a Estatística pode abarcar. O pragmatismo presente desde a gênese de muitas das técnicas desenvolvidas nesse campo, suas possibilidades de aplicação em áreas e contextos diversos, seu tipo especial de raciocínio, diferente do matemático, seus usos para subsidiar tomadas de decisão no campo das políticas econômicas e sociais, por exemplo, são algumas das razões que podem conferir ao ensino da Estatística tornar-se um campo fértil para a implementação de muitas das ideias defendidas por educadores.

A interdisciplinaridade, a contextualização, a utilização de tendências metodológicas como as Atividades Investigativas, a Resolução de Problemas, a Modelagem Matemática, os Cenários para Investigação são ideias que, a nosso ver, são convergentes com um ensino de Estatística que pode considerar assim a natureza dessa ciência. Lopes (2013, p. 905) afirma que: "Para ensinar estatística, não é suficiente entender a teoria matemática e os procedimentos estatísticos; é preciso fornecer ilustrações reais aos estudantes e saber como usá-las para envolver os alunos no desenvolvimento de seu juízo crítico”.

Para Batanero (2006), a inserção dos conteúdos Estatística e Probabilidade nos currículos de Matemática na Educação Básica se justificam pela "utilidade na vida diária, seu papel instrumental em outras disciplinas, a necessidade de um conhecimento estocástico básico em muitas profissões e o importante papel da Estatística no desenvolvimento de um pensamento crítico" (p. 63).

Em face dessas considerações, nossas pretensões estavam relacionadas à elaboração e implantação de uma proposta didática alternativa para o processo de ensino e aprendizagem de Estatística que levasse em conta:

1) a riqueza e diversidade de suas aplicações práticas em diversas áreas do conhecimento, bem como no próprio método científico, considerando-a como um saber imensamente útil para nossa sociedade; 
2) o fato de que há um longo caminho a ser percorrido pelos dados até se chegar às suas representações e ao cálculo de medidas descritivas, e como deles se podem tirar conclusões, ou seja, todo o processo de investigação estatística;

3) a necessidade de uma postura crítica frente às informações que fazem uso da linguagem estatística dada à intensidade com que aparecem na mídia e considerando que existe a possibilidade de se produzirem armadilhas com dados estatísticos e que pode haver erros metodológicos.

Nossa incursão pela literatura pertinente nos levou à concepção de ciclo investigativo PPDAC (Problema, Plan, Datos, Análisis, Conclusiones) adaptado por Wild e Pfannkuch (1999), que faz parte de uma estrutura proposta por esses autores para o pensamento estatístico envolvido nas investigações empíricas, que mostrou-se coerente com aquilo que pensávamos a respeito da aprendizagem estatística podendo, então, atender anseios expressados nas ideias 1 e 2 anteriormente citadas.

Faltava ainda considerar o potencial da Estatística no desenvolvimento do pensamento crítico, que veio a ser traduzido em uma postura crítica diante do uso do conhecimento estatístico na sociedade e sua veiculação na mídia. Ao investigarmos a questão da postura crítica frente às informações estatísticas, acabamos por incorporar uma estrutura maior, de letramento estatístico, no qual tal postura crítica faz parte de seus elementos.

No presente artigo nos propomos então a descrever nossa proposta didáticometodológica, enfocando os fundamentos teóricos que sustentam sua constituição e exemplificando-a através das produções dos estudantes envolvidos em sua implementação fornecendo, assim, subsídios para professores de Matemática da Educação Básica que tenham interesse em sua utilização.

As atividades elaboradas foram realizadas em uma escola da rede pública estadual de Minas Gerais. Fizemos uma intervenção nas aulas de Matemática de uma turma de $3^{\circ}$ ano do Ensino Médio. No que concerne aos aspectos da condução das atividades por parte do professor-pesquisador os referenciais teórico-metodológicos dizem respeito à mediação e à interação nas relações professor-estudantes-conteúdos. Elementos da Educação Matemática Crítica estiveram presentes, como o conceito (e as possibilidades de sua operacionalização) de diálogo, conforme proposto por Alrø e Skovsmose (2006), e também a concepção de atividades cooperativas de Garfield (1993).

Assim, esses aportes nos proveram elementos teórico-metodológicos para uma visão de processo de ensino e aprendizagem subsidiando um foco crítico-reflexivo nas estratégias utilizadas na condução do processo. 
Destarte, o produto educacional que aqui será discutido, desenvolvido junto ao Programa de Mestrado Profissional em Educação Matemática da Universidade Federal de Ouro Preto, teve como motivações iniciais inquietações e questionamentos oriundos de nossa prática docente a partir dos quais se recorreu à literatura acadêmica para sua constituição. Com bases em pesquisas e constructos teóricos pertinentes foi construída uma proposta didática para o processo de ensino e aprendizagem da estatística no Ensino Médio que por sua vez foi implementada, testada e avaliada na prática cotidiana de uma escola pública, em uma turma de $3^{\circ}$ ano deste nível de ensino. Novamente remontamos à academia, à luz dos referenciais teóricos adotadas, para avaliar todo o processo.

\section{Referencial teórico}

Estudos, como Souza (2002), Lopes (1998), Lopes (2003), Mendonça (2008), Biajone (2010), Campos (2007), têm apontado para formas alternativas de abordagem ao ensino que mantém ênfase excessiva nos aspectos computacionais e na memorização de algoritmos e fórmulas, limitados ao tratamento de "dados" sem significação e sem um contexto subjacente. Seja qual for a estratégia de ensino adotada e o nível de ensino em que foram implementadas, são propostas atividades de cunho investigativo em que a contextualização fomenta a aprendizagem dos conceitos. Assim, a partir da realização de investigações - que partem de uma problemática e percorre todo o processo de planejamento, obtenção e análise de dados indo às conclusões e divulgação de resultados -, os conteúdos estatísticos vão sendo apresentados à medida que sua necessidade surja. Defendem-se, desse modo, sequências de atividades que coloquem o estudante numa posição de ação, de resolução de problemas, de tomada de decisões e de autonomia, ao longo de toda a investigação. Almeja-se, nesse contexto, desenvolver competências estatísticas e o pensamento crítico.

Tendo isso em mente, desenvolvemos a fundamentação teórica de nossa proposta norteada pela ideia de proporcionar o envolvimento dos estudantes em uma investigação empírica de caráter estatístico, conduzida com um enfoque crítico-reflexivo, com vistas a que os estudantes apreendessem conceitos estatísticos relevantes e desenvolvessem, também, uma postura mais reflexiva frente às informações estatísticas tão comumente veiculadas na mídia, aprendendo através do fazer, isso é, produzindo estatísticas. Dessa maneira, procurou-se levar o aprendiz à vivência de uma prática (de pesquisa estatística) percebendo suas dificuldades, 
limitações, mas também destacando sua importância e buscando valorizar seus resultados, quando bem feitas, tendo em vista os objetivos estabelecidos.

Apresentamos nas próximas seções as concepções de letramento e de pensamento estatístico adotadas e como elas se enlaçam e se manifestam na construção de nossa proposta.

\subsection{Letramento estatístico}

A concepção de letramento estatístico que foi adotada em nosso estudo é a de Gal (2002). Seu modelo aborda capacidades necessárias a um adulto para que possa posicionar-se de maneira mais conscienciosa em face do alude de informações a que estamos expostos sendo consumidores críticos e utilizadores da informação estatística.

$\mathrm{O}$ autor concebe o letramento estatístico referindo-se a dois componentes interrelacionados. O primeiro relativo à capacidade das pessoas para interpretar e avaliar criticamente a informação estatística, os argumentos relacionados aos dados ou a fenômenos estocásticos, encontrados em diversos contextos. O outro, concernente à capacidade de discutir ou comunicar, quando pertinente, reações às informações estatísticas, tais como sua compreensão do significado da informação, suas opiniões sobre as repercussões dessa informação ou suas considerações com relação à aceitação das conclusões fornecidas.

Pressupõe-se, nesse modelo, a ativação conjunta de cinco bases de conhecimentos inter-relacionadas, quais sejam: habilidades gerais de letramento, conhecimento estatístico, conhecimento matemático, conhecimento do contexto e questionamentos críticos. Além disso, se baseia também na presença de uma postura crítica apoiada em crenças e atitudes.

O conhecimento estatístico considerado necessário está fundamentado em cinco partes: 1- saber por que os dados são necessários e como podem ser produzidos; 2familiaridade com conceitos e ideias básicas relacionadas à estatística descritiva; 3familiaridade com conceitos básicos e ideias relacionadas a representações gráficas e tabulares; 4- compreensão de noções básicas de probabilidade; 5- saber como conclusões ou inferências estatísticas são obtidas.

Gal (2002) trata, contudo, do letramento esperado de pessoas, adultos que já passaram pela escola, em contexto de leitura, que estariam, portanto, na condição de consumidores de informações estatísticas. Estabelecidas, então, as bases de conhecimento, crenças e atitudes que fundamentam o comportamento dos cidadãos estatisticamente letrados, que possam ser consumidores críticos, o desafio que se coloca é como desenvolvê-las nos estudantes. São 
necessárias, portanto, estratégias didático-pedagógicas para a sala de aula que contribuam para esse desenvolvimento.

De acordo com Gomes (2010), a que se considerar as concepções de letramento no ambiente escolar, pois:

No contexto escolar, esses eventos e práticas se tornam objetos de ensino e aprendizagem submetidos a uma organização sistemática, mediante processo de seleção de acordo com critérios pedagógicos, de contextos e atividades a desenvolver e a avaliar, visando alcançar um objetivo primordial: criar oportunidades de aprendizagem para o aluno. Ocorre, assim, a pedagogização do letramento, ou seja, um processo no qual práticas sociais de letramento se tornam sequências didáticas, práticas de letramento a ensinar, posteriormente, ensinadas, e, finalmente, adquiridas (GOMES, 2010, p. 55).

Watson (2006), citado por Almeida (2010), faz eco a essas considerações, pois propõe, com base no modelo de Gal (2002), a "pedagogização do letramento" ao sugerir premissas do letramento estatístico na escola. A primeira delas, conforme Almeida (2010), refere-se à inserção dos conteúdos estatísticos no currículo de Matemática; a segunda, considera que o letramento estatístico pode ser construído juntamente com o desenvolvimento do pensamento estatístico, pensamento crítico, entendimento do contexto e motivação dos estudantes à tomada de decisão; a terceira, por sua vez, traz a responsabilidade do professor no planejamento da aprendizagem dos estudantes e a quarta premissa diz respeito às tarefas e atividades necessárias a construção do entendimento dos conceitos estatísticos com relação a metas e objetivos propostos.

Dessa forma, operacionalizar elementos do modelo de Gal (2002) em sala de aula requer um vivenciar de toda a lógica das investigações estatísticas, com um enfoque críticoreflexivo. Entendemos, assim, que "para letrar estatisticamente o aluno, precisamos também desenvolver o pensamento estatístico, de maneira que o aluno reflita, de forma crítica, sobre todas as fases da pesquisa" (CAZORLA; SANTANA, 2010, p. 13). Lopes (2004) reforça essa ideia, pois afirma que a aquisição de habilidades relativas ao letramento estatístico requer o desenvolvimento do pensamento estatístico que, segundo a autora, permite que a pessoa seja capaz de utilizar ideias estatísticas e atribuir um significado à informação estatística.

\subsection{Pensamento estatístico}

Wild e Pfannkuch (1999) propõem uma estrutura para o pensamento estatístico na qual a primeira dimensão se configurará o arcabouço metodológico das atividades que construímos, conforme trataremos em seguida. Ela se refere a uma adaptação do modelo 
PPDAC (Problem, Plan, Data, Analysis, Conclusions) de Mackay e Oldford (1994) e se relaciona com a forma como uma pessoa atua e o que pensa durante o curso de uma investigação estatística (vide Figura 1). Essa dimensão evidencia a importância da formulação do problema, inserido em um dado contexto, e do planejamento do sistema de medição, plano amostral etc., etapas iniciais do modelo. Além disso, o conhecimento obtido e as necessidades identificadas dentro do ciclo podem originar novos ciclos investigativos.

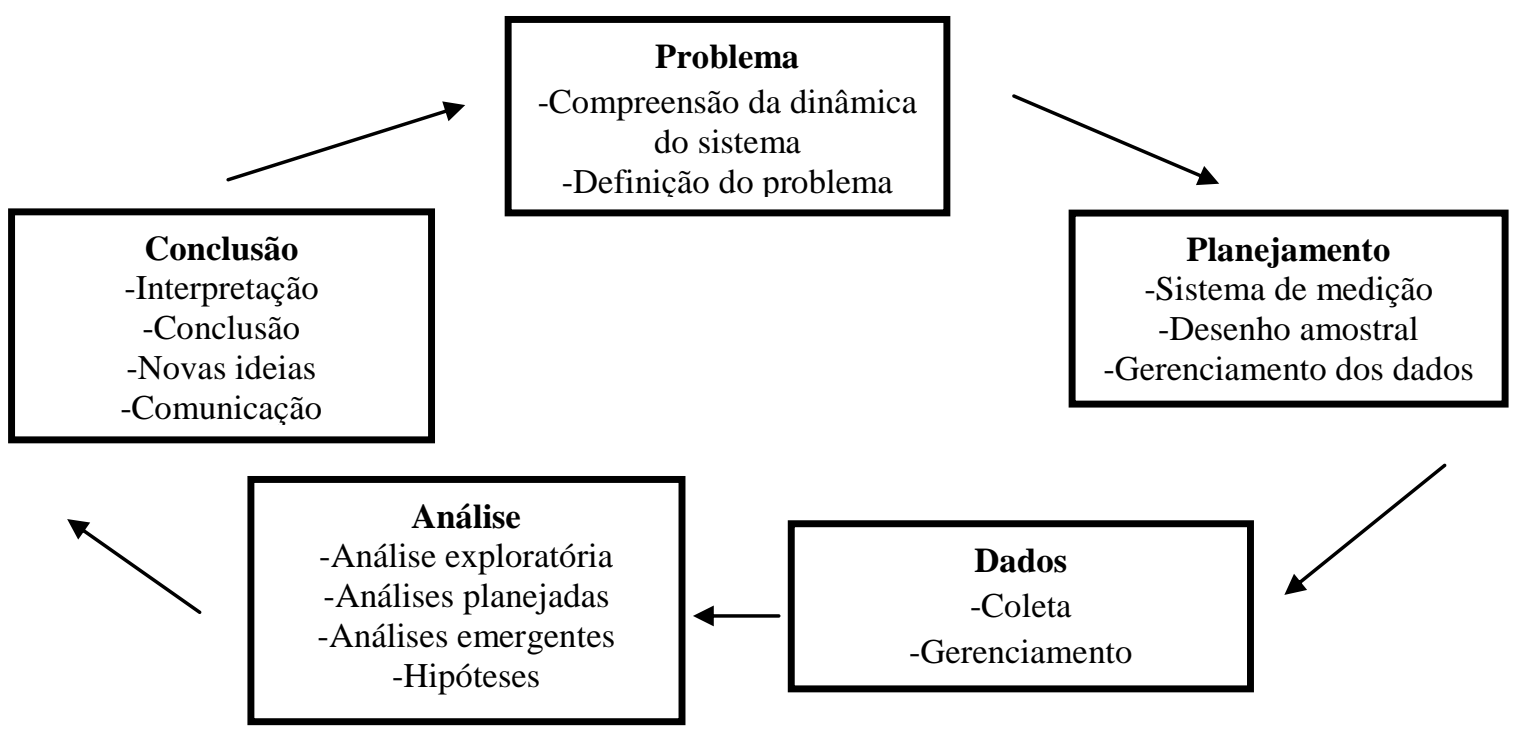

Figura 1 - Esquema representando o ciclo investigativo Fonte: Wild e Pfannkuch (1999)

Silva (2007) entende que esse modelo, em se tratando do uso didático, objetiva que o estudante sinta necessidade de resolver um problema, o que poderá garantir seu envolvimento. Dessa forma, o problema deixaria de ser resolvido apenas porque o professor o pede, pois o estudante estando envolvido passaria a desejar a solução e buscaria ferramentas necessárias para isso. Concordamos em grande medida com essa afirmação, já que o compromisso e o envolvimento com o problema são condições importantes para que o pensamento estatístico se desenvolva (WILD; PFANNKUCH, 1999).

De acordo com Wild e Pfannkuch (1999), a matéria-prima com que trabalha o pensamento estatístico envolve o conhecimento estatístico, do contexto e a informação oriunda dos dados. O pensamento em si é a síntese desses elementos para produzir implicações, ideias e conjecturas. As etapas iniciais do ciclo são conduzidas quase que completamente pelo conhecimento do contexto. O conhecimento estatístico, por sua vez, contribui mais à medida que o pensamento se materializa e que se estabelece um diálogo constante nas esferas do contexto e da Estatística por meio do processo PPDAC. Daí a necessidade de contextualização das atividades ao se trabalhar com o ciclo. 
Concluímos que um conjunto de atividades norteadas por este ciclo garante que os estudantes se envolvam em um processo de investigação estatística, do problema às conclusões, contextualizado, em que os conceitos vão sendo estudados à medida que se avança nas etapas do modelo PPDAC, sendo que o contexto investigado motiva as escolhas.

Dessa forma, encontramos nessa estratégia uma metodologia didático-pedagógica adequada à apreensão dos conteúdos e ao desenvolvimento do letramento estatístico, sustentada pela problematização e contextualização e conduzida com base no diálogo e cooperação entre os participantes.

Propomos, então, uma abordagem reflexiva, contextualizada, onde os conceitos emergem do caráter investigativo das atividades, surgem à medida que se estuda determinado tema escolhido pelos estudantes, aplicando-se as técnicas estatísticas. Desse modo, situações reais motivam e justificam o ensino desse conteúdo no Ensino Médio.

\section{Procedimentos metodológicos}

Antes de passarmos à descrição e análise da proposta construída, trataremos dos procedimentos metodológicos utilizados em seu teste avaliativo. As atividades foram desenvolvidas em uma escola pertence à Rede Estadual de ensino que está localizada na cidade de Carlos Chagas, Minas Gerais. Realizamos uma intervenção nas aulas de Matemática de uma turma de $3^{\circ}$ ano do Ensino Médio, já que esse nível de ensino era nosso alvo, no ano letivo de 2010. Antes, porém, realizamos um projeto piloto em outra turma dessa mesma escola. Dessa forma, utilizamo-nos dos horários regulares, com o apoio e colaboração do professor que nos cedeu as aulas, sendo essa parceria um ponto crucial para consecução das atividades de campo. Além disso, tal fato possibilitou que a nossa proposta fosse realizada em um contexto mais fiel à rotina escolar.

A dinâmica na sala de aula consistiu da realização de atividades em grupos de 3 ou 4 estudantes nas quais eram colocadas questões a serem investigadas por eles sempre mediados pelo professor-pesquisador. Nesse sentido, era atribuída aos estudantes certa autonomia de fazer suas escolhas, mas sempre buscando justificá-las. Em geral, ao final eram elaborados relatórios escritos sobre suas conclusões e, algumas vezes, socializados e discutidos com toda a turma. Os encontros eram sempre gravados em áudio, alguns também em vídeo.

Desse modo, nos pautamos na utilização de atividades investigativas em grupo, elaboração de relatórios visando ao exercício da comunicação (estatística) escrita, debates sobre as escolhas feitas nas fases da investigação com o propósito de exercitar a 
argumentação e refletir sobre as possibilidades de uso do conhecimento estatístico, tomadas de decisão, uso de planilha eletrônica (BrOffice Calc), pesquisa extraclasse, entre outras estratégias para sala de aula conforme apontam nossos referenciais.

Consonante com o objetivo proposto neste artigo, passaremos à apresentação das ideias que fundamentaram nossas escolhas no que concerne à postura do professor na condução das atividades e também dos estudantes. Em seguida, procederemos à descrição das atividades e apresentação de algumas produções dos estudantes.

\section{Condução das atividades}

Enfocaremos três aspectos em seguida: comunicação, interação e avaliação. Neles, mais do que embasamento teórico para a condução de nossas atividades, encontramos uma ressignificação do nosso papel em sala de aula, da nossa visão enquanto educador. Percebemos, no lidar com os estudantes, o quanto tais aspectos contribuíram para a eficácia da proposta e o quanto ainda precisávamos aprimorá-los revendo posturas tradicionais tão arraigadas em nossa prática.

\subsection{Comunicação e aprendizagem}

A Educação Matemática Crítica (EMC), proposta por Ole Skovsmose, vem desempenhar um importante papel ao se pensar metodologias alternativas ao padrão tradicional no ensino da Matemática, uma vez que implica a quebra de paradigmas tradicionais; dirige certo olhar para a aprendizagem e propõe novos paradigmas.

No modelo de ensino tradicional apresentado por Alrø e Skovsmose (2006), as aulas de Matemática costumam seguir certo padrão. Primeiro, asseveram os autores, o professor apresenta algumas ideias e técnicas matemáticas, geralmente em conformidade com um livrotexto. Em seguida, os alunos fazem alguns exercícios pela aplicação direta das técnicas apresentadas. Na sequência, o professor confere as respostas e uma parte essencial do trabalho de casa é resolver exercícios do livro.

De acordo com Skovsmose (2007), o ensino tradicional da Matemática sustenta que todas as competências matemáticas do nível escolar têm que ser desenvolvidas (ou construídas) a partir de um conjunto de exercícios preestabelecidos. A esse aspecto Alrø e Skovsmose (2006) se referem como o paradigma do exercício. Defendem, ainda, que esse paradigma tem grande influência na Educação Matemática no que concerne à organização das 
aulas, aos padrões de comunicação entre professor e estudantes, bem como ao papel que a Matemática desempenha na sociedade.

Configura-se nesse cenário um padrão de comunicação definido por Alrø e Skovsmose (2006) como comunicação "sanduichada": O professor faz uma pergunta, o estudante responde, e o professor avalia a resposta. Constitui-se, também, um absolutismo burocrático, que estabelece em termos absolutos o que é certo e o que é errado sem, no entanto, explicitar os critérios que orientam tais decisões. Assim, todo o processo vai sendo, em geral, conduzido em termos de "ordens" e prescrições.

Na perspectiva da EMC a aprendizagem deve se basear na interação e no diálogo. Isso irá implicar que a relação entre professor e estudantes e entre estudante e estudante deverá se dar com base no diálogo e na cooperação.

Para Alrø e Skovsmose (2006), o diálogo se caracteriza por realizar uma investigação, correr riscos e promover a igualdade. Em oposição ao paradigma do exercício são propostos os cenários para investigação. Cenários que podem, assim, substituir exercícios. Os alunos podem formular questões e planejar linhas de investigação de forma diversificada. Eles podem participar do processo de investigação.

É possível realizar uma investigação nos mais diversos assuntos, com o propósito de obter conhecimento. Dessa forma, privilegiar o diálogo significa prestigiar certo tipo de investigação, e esse tipo de investigação tem muito a ver com os participantes, através de seus pensamentos e sentimentos, entendimentos e pressupostos a respeito das coisas, das ideias e das possibilidades. No diálogo, é importante explorar as perspectivas dos participantes como fontes de investigação (ALRØ; SKOVSMOSE, 2006, p. 125).

Para um professor participar de um diálogo em sala de aula, ele não pode ter respostas prontas para problemas conhecidos, deve ter curiosidade a respeito do que os alunos fariam e estar disposto a reconsiderar seus entendimentos e pressupostos (ALRØ; SKOVSMOSE, 2006).

Nesse contexto, igualdade se refere à ideia de que discussões, afirmações e boas razões não têm um poder especial apenas por serem estabelecidos por alguém que está numa posição mais "poderosa". Isto é, qualquer discussão ou afirmação pode obter força apenas a partir de seu próprio conteúdo e não a partir das pessoas (ou posições) que a apresentem.

É preciso, assim sendo, uma mudança de postura do professor diante dos estudantes, da Matemática (da Estatística em particular) e do seu ensino. Aprimorando a forma de comunicação e interação torna-se possível proporcionar uma melhor aprendizagem. 


\subsection{Atividades cooperativas: a interação}

Garfield (1993) apresenta importantes ideias para a operacionalização de investigações em sala de aula convergentes com as ideias defendidas por Ole Skovsmose e que tentamos nos apropriar. A autora sugere o uso de atividades de aprendizagem cooperativa em grupos como uma forma de se promover uma aprendizagem ativa, na qual os estudantes são capazes de construir conhecimento, complementando ou mesmo substituindo aulas tradicionais.

A autora observa que nesse tipo de atividade o papel do professor muda, passando de "fonte de informação" para "facilitador da aprendizagem". Ele se torna um assessor no curso da aprendizagem do estudante.

Como forma de explicitar essa afirmação, Garfield (1993) sustenta que nas atividades em grupo cooperativo, ao observar os estudantes enquanto trabalham em seus grupos, o professor pode percebê-los expressarem sua compreensão do que aprenderam fornecendo-lhe informações para uma avaliação de como os alunos estão aprendendo as ideias e conceitos.

Relatórios escritos sobre as atividades do grupo também podem ser usados para avaliar a capacidade dos alunos em resolver um problema particular, aplicar uma habilidade, demonstrar compreensão de um conceito importante, ou usar as habilidades de raciocínio.

Um modo de usar grupos cooperativos no ensino de Estatística, de acordo com a autora, é desenvolver atividades que envolvam os grupos em um grande projeto de coleta, análise e interpretação dos dados. Os grupos podem se reunir na sala de aula ou fora dela para trabalharem nesses projetos, e podem apresentar os resultados em um relatório escrito e / ou em apresentação oral em sala de aula.

Trabalhar em conjunto com colegas estimula a comparação de diferentes soluções para problemas estatísticos e das estratégias de resolução de problemas e as formas de entender problemas particulares (GARFIELD, 1993). Isso permite que os estudantes aprendam em primeira mão que não há apenas uma maneira correta de resolver a maioria dos problemas estatísticos. Além disso, essa prática também deve proporcionar aos alunos oportunidades de expressar verbalmente seu entendimento acerca daquilo que aprenderam.

É importante, todavia, ressaltar que nem toda atividade em grupo constituirá necessariamente uma aprendizagem cooperativa. De acordo com Johnson et al. (1991), 
citados por Garfield (1993), ela não acontece se os alunos sentam-se lado a lado na mesma mesa para conversar uns com os outros, mas fazendo seus trabalhos individualmente, numa situação em que aqueles que terminam primeiro são instruídos a ajudar os alunos mais lentos; ou ainda quando a um grupo é solicitado um relatório e somente um estudante faz todo o trabalho do grupo e os demais apenas colocam seus nomes nele.

\subsection{Sobre a avaliação}

Professor e estudantes devem estar cientes que os problemas estatísticos podem ser resolvidos de formas diferentes, bem como que podem aprender uns com os outros por meio da comparação das diferentes formas de pensamentos que surgirem.

Imbuído dessa ideia, além de atribuir devida relevância à comunicação e à interação, o professor deve ter em mente, também, que é necessário avaliar continuamente, esclarecendo já de antemão os critérios que serão utilizados para esse fim. É necessário, dessa forma, definir a priori critérios de avaliação.

Mesmo sob a motivação de estarem trabalhando em algo de seu interesse, poderá haver grupos que não se empenharão; ou estudantes, individualmente, que não se envolverão no processo, a despeito de que muitas vezes cobram do professor atividades diferentes das tradicionais (BIAJONE; CARVALHO, 2005).

Desse modo, para garantir a integridade do projeto é importante estabelecer critérios de avaliação que poderão consistir na quantificação das tarefas individuais - relatadas em um diário denominado "Tarefas do aluno" (esse se configurando também um instrumento de coleta de informações para a pesquisa) - e do grupo, ambas realizadas em aula a aula, que na verdade serão as atividades necessárias para a realização das várias fases do ciclo investigativo.

Defendemos a importância (e a possibilidade) da avaliação continuada no decurso das atividades. Não devemos ficar restritos aos exames escritos objetivos, mas avaliar no dia a dia da sala de aula mediante atividades específicas que evidenciem o desenvolvimento de capacidades (CAMPOS, 2007). Isso pode ser feito mediante discussões e debates sobre as interpretações e análises mais adequadas a cada fase do ciclo, como também através de relatórios escritos feito a partir das discussões do grupo etc., conforme afirmamos no parágrafo anterior. 


\section{Descrição das atividades}

Apresentamos agora o planejamento do ciclo investigativo mostrando as etapas utilizadas para implementar tal estratégia.

A partir do entrelaçamento teórico entre os aspectos do conhecimento estatístico do modelo de Gal (2002) e as fases do ciclo investigativo de Wild e Pfankuch (1999) planejamos as atividades, que começam com a escolha de temas para o estudo e estabelecimento de seus objetivos, indo às conclusões, divulgação dos resultados à comunidade escolar e avaliação da credibilidade das estatísticas produzidas.

Assim, definido(s) o(s) tema(s) e estabelecida uma questão relevante a ser investigada, o passo seguinte concentra-se no planejamento, discutindo, entre outras coisas, se o levantamento será feito a partir de um censo ou de uma amostra, bem como o tipo de amostragem que será empregado, método de coleta etc. Coletados os dados, estes deverão ser tabulados e analisados, estudando-se aspectos descritivos e/ou calculando-se estimativas - as estatísticas. Finalmente, são realizadas as análises, discussões e tomada de decisão, enfim, as inferências.

Sistematicamente, eis a sequência das atividades, apresentada passo a passo, seguindo a lógica das fases do ciclo investigativo. Ao mesmo tempo mostramos como foi feito no teste avaliativo.

\section{1- Problematização:}

$\left.1^{\circ}\right)$ divisão da turma em grupos e escolha dos temas;

$\left.2^{\circ}\right)$ busca por maiores informações sobre o tema para estudá-las/discuti-las e estabelecer os objetivos (ou questões problema) do estudo.

Nessa fase o ponto de partida foi uma apresentação com o propósito principal de aguçar a curiosidade dos estudantes acerca da Estatística, buscando assim proporcionar um ambiente mais motivador para a aprendizagem. Destacamos a relevância das pesquisas estatísticas e discutimos sua veiculação pela mídia. Essa apresentação inicial propiciou que os estudantes reconhecessem a relevância (objetiva) do conteúdo (Estatística) que seria estudado. Mostraram-se curiosos com relação aos temas discutidos enquanto, enfileirados nas carteiras, ouviam com grande atenção nossa fala. Algumas vezes faziam algumas intervenções levantando questionamentos.

Por fim foi apresentada a proposta de trabalho - como um convite à realização de uma investigação estatística, à semelhança do que é feito em uma pesquisa de intenção de votos com o intuito de: aprender com a prática; vivenciar a lógica das investigações estatísticas, isso 
é, como são conduzidas e desenvolvidas de modo que se possam apreender os conceitos estatísticos - matéria do currículo - e compreender o processo de geração das informações estatísticas. Passamos, então, à formação dos grupos e à escolha dos temas para o estudo que os estudantes fariam. Ficou a cargo deles a organização dos grupos no sentido da escolha dos parceiros, porém condicionados a um número de 3 ou 4 integrantes.

Para iniciar o ciclo investigativo procuramos dar voz ativa aos estudantes permitindo que sugerissem e escolhessem os temas a serem investigados a fim de que se garantisse maior valor subjetivo para o trabalho e que assim ficassem mais motivados a investigá-los, mais por interesse do que por imposição. Todavia, para estimulá-los, começamos mostrando algumas possibilidades e dando exemplos de questões que poderiam ser pesquisadas dentro dos temas exemplificados. O intuito era incentivar que deles surgissem outras ideias. Violência, drogas, acessibilidade, bullying, corrupção, consumismo foram temas sugeridos por eles. Na aula seguinte entregamos um caderno, que denominamos portfólio de atividades, para cada grupo avisando que sempre que fosse solicitado deveriam ali registrar os relatórios das atividades realizadas.

A partir daí foi solicitado que cada grupo definisse um objetivo, um tópico subordinado ao tema que tivessem interesse em conhecer mais a fundo, que poderia ser expresso como uma pergunta.

\section{2- Planejamento:}

\section{$\left.3^{\circ}\right)$ Definir a população-alvo para o estudo.}

Foi pedida, em sequência, a escolha da população-alvo do estudo - Qual seria o público alvo a ser pesquisado no estudo? - dando início, assim, à fase de planejamento do ciclo investigativo.

Aqui o professor define o conceito de população a partir do contexto da investigação.

As respostas colocadas pelos grupos foram discutidas posteriormente, confrontadas e aprimoradas em discussão com toda a classe a fim de se escolher a que fosse mais adequada tanto o objetivo como a população-alvo. Para essa última, mais que isso, discutiu-se se estava perfeitamente definida, ou seja, se se tinha uma característica que determinava o conjunto de elementos que seria essa população. Enfim, definimos nesse momento o conceito de população estatística.

A partir desse momento passaremos a enfocar aquilo que foi produzido por dois dos grupos, o primeiro com o tema consumismo e o segundo com o tema internet.

Para o tema internet o resultado foi o seguinte:

Objetivo: Qual o perfil do jovem internauta estudante de Ensino Fundamental e médio? 
População-alvo: Estudantes de uma escola de Ensino Fundamental e de uma escola de Ensino Médio.

Para o tema consumismo chegou-se ao seguinte resultado:

Objetivo: Quais aspectos do consumismo se manifestam em pessoas de 12 a 26 anos do município de Carlos Chagas?

População-alvo: Cidadãos do município de Carlos Chagas da faixa etária de 12 a 26 anos

Enquanto os estudantes que investigavam o tema internet preferiram limitar o estudo pesquisando apenas na própria escola e em outra bem próxima, os grupos, especialmente o grupo 1, que pesquisavam consumismo defenderam incisivamente um público mais abrangente.

$4^{\circ}$ ) Censo $x$ amostragem.

Foi utilizada, nesse momento, a seguinte problematização: Considerando-se a suposição de que o grupo faz parte da diretoria de um Instituto de Pesquisa ao qual esse estudo foi encomendado, discutir a conveniência de se fazer essa investigação através de um censo ou de uma amostragem apontando possíveis vantagens e desvantagens de cada um nesse trabalho. (Para essa atividade o professor e os estudantes deverão estudar/discutir as vantagens e desvantagens do censo e da amostragem previamente).

Essa atividade foi resolvida através da discussão em grupo e o resultado expresso por escrito em um relatório contendo a solução. A partir do contexto os estudantes estabeleceram possíveis vantagens para um estudo por amostragem e, desse modo, fizeram uma escolha e adquiriram uma noção com base em um contexto. Além disso, começaram a dar indícios de percepção da necessidade de inferir a partir de amostras de uma população:

Grupo1: Uma amostra para esse tipo de pesquisa é mais viável, pois a população geral é muito extensa, então realizaremos uma amostra com uma pequena parte dessa população que também vai nos render um bom resultado, com uma pequena margem de erros.

Grupo3: Fazer o censo demoraria mais tempo, traria mais trabalho, poderia apresentar erros [se referindo ao menor controle nos procedimentos de campo], teria que ter mais pessoas, gastaria mais materiais (Caderno Tarefas do aluno, 2010).

$5^{\circ}$ ) Uma vez decidido que as investigações se dariam por meio de amostragem, passamos à elaboração dos planos amostrais. A dinâmica para essa fase do trabalho consistiu, primeiramente, em estudo de textos sobre algumas técnicas de amostragem para, em seguida, os estudantes apontarem a técnica mais viável à investigação proposta e apresentar para a turma. O problema colocado foi o seguinte: definida a amostragem como o melhor caminho, de que modo então selecionar aleatoriamente a amostra para nosso estudo? Caso o grupo 
perceba que as técnicas de amostragem probabilísticas não são convenientes, justificar o porquê e propor uma alternativa, isso é, uma amostragem não probabilística.

Durante a apresentação dos planos amostrais íamos fazendo alguns questionamentos aos estudantes - que se mostraram bastante tímidos, devido às filmagens. As questões que colocávamos contribuíram um pouco para que ficassem mais à vontade ao mesmo tempo em que refletiam sobre as escolhas feitas. Por exemplo, questionamos: foi possível (ou viável) elaborar uma amostra probabilística para essa população? Qual tipo de amostragem? Como proceder a seleção dos elementos nessa amostragem? Se a amostragem escolhida era a Estratificada, questionamos: quais estratos? Porque esses estratos? Quantos elementos nos estratos? Como selecioná-los? Se era por conglomerados: Quais os conglomerados? Como sorteá-los? Quantos? Se era Aleatória Simples: Como enumerar todos os elementos da população de 1 a $\mathrm{N}$ ? Como sortear os $\mathrm{n}$ elementos da amostra? No caso da amostragem sistemática, questionamos, por exemplo: quantas amostras diferentes seriam possíveis?

Vejamos as conclusões dos grupos em análise:

Grupo1: Nenhuma das amostras probabilísticas, por que é necessário que haja uma aglomeração de jovens em determinado local e determinada hora, para que seja realizada uma seleção aleatória entre os jovens de tal aglomeração.

Usaremos Amostra não probabilística

Amostragem acidental: é a amostragem na qual não se tem seleção prévia dos elementos a serem entrevistados. A escolha é feita ao acaso (acidentalmente).

Essa amostra nos beneficiará por não ter que realizar uma seleção prévia dos elementos entrevistados, ocorrendo a escolha aleatória dos elementos em uma aglomeração de pessoas.

Grupo3: Amostragem Sistemática

$N=1000: 150 \approx 6,6 / 7$

Primeiro pega-se o número total de alunos das duas escolas $(N=1000)$ e deseja-se extrair uma amostra $n=150$ [valor tomado como base para o cálculo]. Divide-se os números e o total, que no exemplo [o resultado] é 7 . Assim se o número 3 for o primeiro a ser sorteado entre os 7 primeiros a amostra fica determinada da seguinte forma (3, 10, 17, 24) (Caderno Tarefas do aluno, 2010).

$6^{\circ}$ ) Em seguida passamos à elaboração dos questionários cabendo ao professorpesquisador apresentar e discutir as variáveis estatísticas e aos estudantes elaborar o questionário propondo questões, levando em consideração variáveis quantitativas e qualitativas.

Mais uma vez em discussão com a turma, refletimos sobre as perguntas que propuseram para o questionário, analisando a pertinência de cada uma ao objetivo que ficou estabelecido para os temas e, assim, com base naquilo que os estudantes sugeriram/opinaram organizamos as perguntas, chegando às versões finais dos questionários a serem utilizados.

Evitamos impor aos estudantes qualquer visão de um questionário mais adequado para aquelas investigações, optando por tentar fazê-los perceber isso, pois o maior interesse era o 
processo de elaboração e não o produto final. Além disso, por acreditar que possíveis falhas no questionário, se identificadas por eles, proporcionariam reflexões acerca da necessidade de que este deva ser bem elaborado em um estudo.

$7^{\circ}$ ) Obtidos os questionários colocamos em debate questões relativas aos procedimentos de campo nesse tipo de pesquisa, como a importância de se treinar adequadamente os entrevistadores e supervisionar os trabalhos; falamos sobre cuidados iniciais e abordagem do informante, conquista da confiança, desenvolvimento da entrevista, encerramento da entrevista, etc.

Isso foi importante também porque entrevistas seriam feitas por eles fora da escola, segundo ficou decidido.

Pesquisador: Então vamos começar pela entrevista. Por quê? A princípio a pessoa que vocês vão entrevistar não tem nada a ganhar com aquilo ali. Pelo menos a princípio não tem nada a ganhar com isso. Então o que poderia levar a pessoa conceder a entrevista? Alguns alunos: Dar um agrado a ela. [risos] Pesquisador: O orçamento não permitiria. Isso aumentaria o custo da pesquisa. [Vários alunos conversando ao mesmo tempo.]

Júlio: Eu falaria do meu trabalho. Pesquisador: Sim, por que a pessoa pode conceder a entrevista se achar que é relevante o seu conteúdo. A pessoa pode achar que aquele assunto que você está entrevistando é importante. É um motivo para ela conceder a entrevista. Muito bem. O que mais? Quais outras motivações a pessoa poderia ter para conceder a entrevista? No momento em que vocês serão os entrevistadores.

Uma das razoes é a pessoa entender, como vocês disseram, a relevância da pesquisa. Júlio: Eu acho que o mais importante é fazer a pessoa acreditar. Pesquisador: Esse pode ser um ponto chave. Em um daqueles vídeos que nós vimos mostrava um entrevistador tentando abordar as pessoas nas ruas e elas se esquivavam. Júlio: Isso não iria acontecer aqui em Carlos Chagas. As coisas são mais calmas aqui. Se a gente explicar que é um trabalho de escola... Joel: Todo mundo conhece todo mundo! (Arquivo das gravações em áudio/vídeo, 2010).

Debater as possibilidades de erros não amostrais possibilitou que os estudantes mobilizassem questionamentos críticos e reconhecessem a chance de maior controle sobre estes ao se usar a amostragem.

\section{3- Dados:}

$8^{\circ}$ ) Os estudantes com o tema internet realizaram as entrevistas dos indivíduos sorteados na amostragem na própria escola, nos três turnos (escola de Ensino Médio), e em outra que fica bem próxima à primeira (escola de Ensino Fundamental). Já os grupos de tema consumismo as fizeram em diversos locais da cidade, em pontos e horários estratégicos, como nas praças, em frente a escolas, durante o desfile de 7 de setembro, entre outros.

Foi um total de 90 entrevistas feitas pelos estudantes do tema Internet e 111 pelos do tema Consumismo ao longo de pouco mais de uma semana. Paralelamente à realização das entrevistas começamos os trabalhos de tabulação dos dados $\left(9^{\circ}\right)$ inserindo-os (na planilha 
eletrônica $\mathrm{Calc}$ ) à medida que os estudantes iam realizando-as. Os grupos foram divididos em duplas a fim de agilizar o trabalho uma vez que cada dupla poderia lançar metade deles.

Percebemos nesse momento um envolvimento muito grande de todos os alunos nessa tarefa. $\mathrm{Na}$ aula do $3^{\circ}$ horário algumas duplas se estenderam ficando o intervalo do recreio fazendo a atividade. Em outro encontro, já no $5^{\circ}$ horário, alguns a princípio, não se deram conta que o horário havia acabado permanecendo minutos após a aula.

\section{4- Análises:}

$10^{\circ}$ ) Nessa fase a atividade ficou assim enunciada: Utilizando os recursos da planilha eletrônica, construir tabelas, tabelas de dupla entrada e respectivos gráficos e o cálculo de medidas descritivas, especialmente a média, para variáveis quantitativas.

Para auxiliar os estudantes nessa tarefa elaboramos um pequeno manual com algumas dicas, para consulta. O que pode ser feito? Como fazer? A primeira parte do manual continha ideias sobre o tipo de representação a que conduz um tipo de variável - as tabelas de frequência, os gráficos e as análises descritivas etc. A segunda parte apresentava algumas dicas de como criar essas representações na planilha que estávamos utilizando. Fizemos para esse fim um resumo com os principais tópicos necessários ao desenvolvimento das atividades, construção de tabelas dinâmicas, inserção de gráficos etc.

Tivemos alguma dificuldade para instruir os estudantes a prestarem atenção no tipo de variável que estavam representando, pois a preocupação maior era com os comandos da planilha a fim de construir tais representações. Todavia, na aula em que se deu o último encontro no laboratório de informática, nos dispusemos a atender os grupos que sentiram a necessidade de mais tempo para concluir essa atividade, dando plantão em outro turno. $\mathrm{O}$ horário foi sugerido por eles sendo preciso, assim, atendê-los no vespertino e noturno.

Esse atendimento extraturno foi um momento especial em que pudemos refletir com os estudantes o fato de que não ter sido possível primeiro analisar o tipo de variável que estavam representando para, a seguir, escolher o tipo de representação mais adequada e as medidas descritivas. Fizemos, ainda, as primeiras interpretações desses dados com questionamentos que podem ser resumidos na pergunta: Você tem aqui essa variável resumida na tabela e/ou representada nesse gráfico, o que tais representações indicam a cerca da população investigada tendo em vista o objetivo da investigação? Demos ênfase às tabelas com variáveis cruzadas, por exemplo: A finalidade de uso da internet difere entre homens e mulheres? As preferências de consumo diferem de acordo com a escolaridade? Entre outras.

$11^{\circ}$ ) Novamente em sala de aula, os estudantes, em grupos, interpretaram as representações e/ou medidas por eles feitas. 


\section{5- Conclusões:}

$\left(12^{\circ}\right)$ Mas, e a margem de erro? Qual sua origem? Como determiná-la? Esses questionamentos deram início a esta fase do trabalho. Falamos novamente do processo de inferência estatística - População (parâmetros) $\Rightarrow$ Técnicas de Amostragem aleatória $\Rightarrow$ Amostra (estimativas) $\Rightarrow$ Inferência (estimação) $\Rightarrow$ População - e mostramos o cálculo do erro amostral para proporções utilizando os dados da investigação. Dessa maneira, mais uma vez contextualizamos os conceitos, utilizando-nos, nesse caso, de duas das tabelas produzidas pelos grupos, uma de cada tema.

Em seguida cada estudante recebeu uma folha de atividades para calcularem o erro para outras categorias da mesma tabela. Depois calcularam a margem de erro supondo outros tamanhos de amostras - 400 e 1000 - com a finalidade de discutir com os colegas de grupo, a partir dos resultados obtidos, a influência do tamanho da amostra. Além disso, calcularam, ainda, a margem de erro com diferentes Índices de Confiança, 95\% e 99\%.

Reproduzimos a atividade feita por uma estudante do grupo 1, transcrita do diário “portfólio de atividades”, donde ela conclui após efetuar os cálculos:

Joana: A proporção de jovens de Carlos Chagas que prefere aparelhos eletrônicos é de $9 \%$ a $21 \%$ [15\% $\pm 6 \%]$, com confiança de $95 \%$.

Com confiança de 95\%, a proporção de jovens de Carlos Chagas que preferem alimentos é de $1 \%$ a $9 \%$.

$$
\begin{aligned}
& e=2 \cdot \sqrt{\frac{0,15(1-0,15)}{111-1}} \quad e=2 \cdot \sqrt{\frac{0,15 \cdot 0,85}{110}} \quad e=2 \cdot \sqrt{\frac{0,1275}{110}} \quad e=2 \cdot \sqrt{0,001159} \quad e=2.0,034044 \\
& e=0,068088 \quad e=6 \%(\text { Caderno Tarefas do aluno, 2010). }
\end{aligned}
$$

A seguir apresentamos o cálculo feito por um estudante do grupo 3, no qual ele compara a margem de erro para diferentes tamanhos amostrais e para diferentes Índices de Confiança e conclui com os colegas de grupo:

Relato que, com o I.C. em 95\%, quanto maior a população entrevistada menor a margem de erro. No entanto, quando se aumenta o I.C. para $99 \%$ a margem de erro aumenta, ainda que o índice de confiança seja maior (Caderno Tarefas do aluno, 2010).

Para que os estudantes tivessem uma visão global da investigação estatística realizada, contribuindo para que soubessem por que os dados são necessários e como podem ser produzidos, solicitamos aos grupos $\left(13^{\circ}\right)$ elaborar um relatório estatístico considerando: questão investigada (objetivo); população-alvo; tamanho e seleção da amostra; variáveis; instrumento de coleta de dados; as perguntas na íntegra; data e local da coleta; apresentação e representação dos dados; índice e intervalo de confiança.

Segue transcrição dos relatórios elaborados pelos grupos 1 e 3 . 
Grupo1:Nosso objetivo era descobrir aspectos de consumismo entre os jovens de 12 a 26 anos da cidade de Carlos Chagas. Foi realizada uma pesquisa [amostragem] não probabilística, a amostragem acidental (é a amostragem na qual não se tem seleção prévia dos elementos a serem entrevistados. A escolha é feita ao acaso (acidentalmente)). Foram entrevistados 111 elementos. Continha na pesquisa as variáveis: sexo, idade, estado civil, trabalha (sim/não), moradia, escolaridade, gastos com dinheiro extra, quantos aparelhos celulares, frequência a festas e restaurantes, necessidade de uma roupa da moda para ir a uma festa. A pesquisa [as entrevistas] foi realizada entre os dias 14 e 22 de setembro, nos seguintes locais: Praça Getúlio Vargas, Escola Estadual Geraldo de Souza Norte, Rodoviária e Praça Castelo Branco. Realizada em locais com maior fluxo de jovens (Caderno Tarefas do aluno, 2010).

A esse texto o grupo acrescentou todos os gráficos e tabelas construídos acrescidos de interpretações. Outros grupos acrescentaram, ainda, as perguntas do questionário.

Grupo 3: O nosso objetivo foi verificar o grau de acessibilidade à internet entre jovens. Nossa população-alvo (fonte de pesquisa) foram alguns alunos do Ensino Médio da Escola Estadual Geraldo de Souza Norte e alunos do Ensino Fundamental da Escola Estadual de Ensino Fundamental. $O$ tipo de amostra escolhida foi a Sistemática, onde os alunos foram escolhidos de acordo com a listagem dada pelo professor, com a lista em mãos escolhemos de 6 em 6 de acordo com o resultado da amostra Sistemática. Foram consultadas 90 pessoas. Das quais 47 do sexo feminino e 43 do sexo masculino com variedades de idade de 11 a 34 anos, com variáveis de tempo [de acesso diário] de 10 minutos a 6 horas, em locais de uso mais frequentes em lan house 51\%. Como instrumento principal de coleta de dados, um questionário que continha questões sobre internet feitas pelos grupos. As pesquisas [entrevistas] foram realizadas entre 14/09 e 15/09. Representando nas tabelas, podemos concluir que ainda que existam muitos meios de se usar internet, ainda existem pessoas sem acesso nenhum à internet. $O$ índice de confiança foi de $95 \%$ e $10 \%$ de margem de erro (Caderno Tarefas do aluno, 2010).

$\left(14^{\circ}\right)$ A divulgação dos resultados foi orientada pela seguinte atividade: o indivíduo comum, em geral, não tem acesso aos dados estatísticos a partir de sua fonte original, os Institutos de Pesquisa. Ele só toma conhecimento desses dados através dos veículos de comunicação. Dessa forma, pede-se que elaborem uma matéria, digamos, a ser publicada em um jornal ou revista. Que dados/resultados apresentariam? De que forma? Que informações acreditam ser relevante o leitor ter acesso? Feitas essas reflexões, elaborar um cartaz apresentando sua matéria jornalística. Elabore título bem criativo e um texto adequado; lembre-se que os textos jornalísticos costumam vir recheados de gráficos e tabelas bem coloridos a fim de ser mais atraente aos leitores; imagine seu trabalho como sendo uma reportagem de capa (no caso de uma revista), por exemplo.

O propósito principal da atividade era que os estudantes se dessem conta que pode haver diferentes possibilidades para a apresentação dos resultados, como relatar alguns dados e esconder outros convenientemente a fim de colocar certo ponto de vista, podendo-se até mesmo maquiar dados apresentando-os de forma enganosa. E que também é possível fornecer informações relevantes no sentido de ajudar o leitor a avaliar melhor o estudo divulgado.

\section{6- Conclusões $\rightarrow$ Problematização:}


$\left(15^{\circ}\right)$ Avaliação da credibilidade das estatísticas produzidas.

Finalizando as atividades, sem perder de vista o enfoque crítico-reflexivo adotado no trabalho, propusemos aos estudantes refletirem sobre a credibilidade dos dados estatísticos produzidos por eles mesmos, deslocando-os para a posição de leitores dos resultados obtidos. Para esse fim foram utilizadas as seguintes questões, aprimoradas após sua implementação: Questões: 1) Os dados obtidos são confiáveis? Justifique. 2) O que é necessário para se ter uma boa pesquisa? 3) Avalie a qualidade do questionário elaborado. 4) Tendo em vista os objetivos que estabelecidos no início, quais são os resultados da pesquisa? 5) Com base no estudo realizado você sugere alguma nova questão a ser investigada?

\section{Considerações finais}

O Produto Educacional aqui apresentado se configura como uma alternativa para o ensino e aprendizagem de Estatística, o qual se dá por meio da contextualização dos conteúdos em atividade de cunho investigativo ao invés de centrar-se na repetição mecânica de algoritmos e procedimentos.

Tal estratégia, fundamentada no desenvolvimento do letramento e do pensamento estatístico, e norteada pelo ciclo investigativo, requer do professor, e também dos estudantes, uma postura diferente do que é tradicional nas aulas de Matemática. O professor deve considerar a comunicação como um aspecto relevante na promoção da aprendizagem e, dessa forma, incorporar à sua prática características dialógicas para a comunicação. Além disso, buscar promover uma maior interação entre os estudantes utilizando-se de atividades de caráter investigativo em pequenos grupos que trabalharão juntos como uma equipe para resolver/investigar um problema, completar uma tarefa, ou realizar um objetivo comum.

No processo de implementação da proposta, concluímos que a mesma favorece ao desenvolvimento de características de letramento estatístico bem como a aprendizagem dos conceitos estatísticos através do fazer, tornando as atividades mais prazerosas e motivadoras para os estudantes. Percebemos que nossos barulhentos estudantes produziram mais do que nos pareceu enquanto os observávamos trabalhando em seus grupos na resolução das atividades. Percebemos, também, o quão difícil foi abandonar o padrão de comunicação sanduichada. Algumas vezes ao chegarmos em casa e ouvirmos as gravações dos encontros identificávamos conversas nas quais poderíamos ter instigado ainda mais as discussões ao invés de "sanduichá-las". Perguntávamos a nós mesmos, ao final dos trabalhos de campo, se 
não era mais difícil para nós do que para os estudantes abandonar o padrão de aula tradicional descrito por Alrø e Skovsmose (2006).

Esperamos enfim que esta proposta possa dar contribuições para o professor de Matemática - especialmente do Ensino Médio, mas também do Fundamental, ou mesmo do Superior - no momento de planejar as atividades que serão realizadas na sua sala de aula.

Esperamos contribuir em alguma medida para que sua missão de ensinar Matemática na Educação Básica, em face de tantas dificuldades encontradas no dia a dia, possa motivar um pouco mais os estudantes à aprendizagem.

\section{Referências}

ALMEIDA, C. C. Análise de um instrumento de letramento estatístico para o Ensino Fundamental II. 2010. 107f. Dissertação (Mestrado em Educação Matemática) - Universidade Bandeirante de São Paulo, São Paulo, 2010.

ALRØ, H.; SKOVSMOSE, O. Diálogo e Aprendizagem em Educação Matemática. Tradução de O. Figueiredo. Belo Horizonte: Autêntica, 2006. (Coleção Tendências em Educação Matemática).

BATANERO, C. Educación Estadística en la matemática escolar: retos para la enseñanza y la formación del profesor (documento de discusión). Revista Iberoamericana de Educación Matemática, Santa Cruz de Tenerife, n. 8, p. 63-75, dic., 2006.

BIAJONE, J. Projeto estatístico na pedagogia. In: LOPES, C. E.; COUTINHO, C. Q. S.; ALMOULOUD, S. A. (Org.). Estudos e reflexões em Educação Estatística. Campinas: Mercado de Letras, 2010. (Série Educação Estatística em Foco). p. 173-192.

BIAJONE, J.; CARVALHO, D.L. Estatística por meio de projetos na pedagogia: caminhos e descaminhos. Educação Matemática em Revista, Recife, n. 18/19, p. 60 - 66, 2005.

CAMPOS, C. R. A Educação Estatística: uma investigação acerca dos aspectos relevantes à didática da estatística em cursos de graduação. 2007. 242 f. Tese (Doutorado em Educação Matemática) - Instituto de Geociências e Ciências Exatas, Universidade Estadual Paulista, Rio Claro, 2007.

CAZORLA, I. M.; SANTANA, E (Org.). Do tratamento da informação ao letramento estatístico. Itabuna: Via Litterarum, 2010. (Alfabetização Matemática, Estatística e Científica).

GAL, I. Adults' Statistical Literacy: Meanings, Components, Responsibilities. International Statistical Review, Voorburg, v. 70, n. 1, p. 1-25, abr. 2002.

GARFIELD, J. Teaching statistics using small-group cooperative learning. Journal of Statistics Education, Alexandria, v. 1, n. 1, 1993. Disponível em: <http://ww2.amstat.org/publications/jse/v1n1/garfield.html> Acesso em: 10 mar. 2015.

GOMES, S. S. Limites e possibilidades do letramento escolar: um estudo etnográfico das práticas de leitura e das capacidades de linguagem nas disciplinas curriculares. 2010.382 p. Tese (Doutorado em Educação) - Faculdade de Educação, Universidade Federal de Minas Gerais, Belo Horizonte, 2010. 
LOPES, C. A. E. A Probabilidade e a Estatística no Ensino Fundamental: uma análise curricular. 1998. 126 p. Dissertação (Mestrado em Educação) - Faculdade de Educação, Universidade Estadual de Campinas, Campinas, 1998.

LOPES, C. A. E. Literacia estatística e o INAF 2002. In: FONSECA, M. C. F. R. (Org.). Letramento no Brasil: habilidades matemáticas. São Paulo: Global, 2004. p. 187-197.

LOPES, C. A. E. O conhecimento profissional dos professores e suas relações com estatística e probabilidade. 2003. 281 f. Tese (Doutorado em Educação) - Faculdade de Educação, Universidade Estadual de Campinas, Campinas, 2003.

LOPES, C. E. Educação Estatística no Curso de Licenciatura em Matemática. Bolema - Boletim de Educação Matemática, Rio Claro, v. 27, n. 47, p. 901-915, dez. 2013.

MACKAY, R. J.; OLDFORD, W. Stat 231 Course Notes Fall 1994. Canada: University of Waterloo, 1994. In: WILD, C.; PFANNKUCH, M. Statistical thinking in empirical enquiry. International Statistical Review, Voorburg, n. 67, p. 223-265, 1999. Disponível em: <http://www. stat.aucland.ac.nz/ iase/publications/isr/99.wild. pfannkuch.pdf>. Acesso em: 24 ago. 2008.

MENDONÇA, L. O. A educação estatística em um ambiente de modelagem matemática no Ensino Médio. 2008. 236 f. Dissertação (Mestrado em Ensino de Ciências e Matemática) Universidade Cruzeiro do Sul, São Paulo, 2008.

SILVA, C. B. Pensamento estatístico e raciocínio sobre variação: um estudo com professores de matemática. 2007. 104 p. Tese (Doutorado em Educação Matemática) - Pontifícia Universidade Católica de São Paulo, São Paulo, 2007.

SKOVSMOSE, O. Educação crítica: incerteza, matemática, responsabilidade. Tradução de M. A. V. Bicudo. São Paulo: Cortez, 2007.

SOUZA, O. Investigações estatísticas no $6^{\circ}$ ano. In: GTI (Ed.), Refletir e investigar sobre a prática profissional, Lisboa: APM, 2002. p. 75-97..

WILD, C.; PFANNKUCH, M. Statistical thinking in empirical enquiry. International Statistical Review, Voorburg, n. 67, p. 223-265, 1999. Disponível em: <http://www. stat.aucland.ac.nz/ iase/publications/isr/99.wild. pfannkuch.pdf>. Acesso em: 24 ago. 2008.

Submetido em Abril de 2015. Aprovado em Janeiro de 2016. 